\title{
A CONJECTURA \\ DE CHIERCHIA \\ E A LOGICIDADE \\ DAS LÍNGUAS \\ NATURAIS
}

\section{LA CONJETURA DE CHIERCHIA Y LA LÓGICA DE LAS LENGUAS NATURALES}

CHIERCHIA'S CONJECTURE AND THE LOGICALITY OF NATURAL LANGUAGES

O objetivo central da ciência é clarificar, da melhor forma possivel,

o funcionamento do mundo natural.

A ciência não tem como missão responder a todas as perguntas.

(Marcelo Gleiser, A ilha do conhecimento.

Os limites da ciência e a busca por sentido)

Roberta Pires de Oliveira*

Universidade Federal do Paraná | Universidade Federal de Santa Catarina

RESUMO: Este artigo apresenta a conjectura de Chierchia (2013), segundo a qual a distribuição e a interpretação de itens escalares, itens de livre escolha, itens de polaridade e implicaturas são condicionados pelo contexto lógico em que eles ocorrem. Em contextos de acarretamento para baixo, a exaustão de alternativas não produz contradição gramatical, enquanto que em contextos de acarretamento para cima, produz uma contradição gramatical. Mostramos que a conjectura prediz corretamente julgamentos intuitivos desses itens no Português Brasileiro e explica os resultados experimentais de Pires (2018) para os modais no Português Brasileiro.

PALAVRAS-CHAVE: Semântica de alternativas. Conjectura de Chierchia. Indefinidos. Modais. Lógica.

RESUMEN: Este artículo presenta la conjetura de Chierchia (2013), según la cual la distribución e interpretación de elementos escalares, elementos de libre elección, elementos de polaridad e implicaturas son condicionados por el contexto lógico en el que ocurren. En contextos de acarreo hacia abajo, el agotamiento de las alternativas no produce contradicción gramatical, mientras que, en contextos de acarreo hacia arriba, produce una contradicción gramatical. Mostramos que la conjetura predice correctamente los 
juicios intuitivos de estos elementos en portugués brasileño y explica los resultados experimentales de Pires (2018) para los modales en portugués brasileño.

PALABRAS CLAVE: Semántica de alternativas. Conjetura de Chierchia. Indefinidos. Modales. Lógica.

ABSTRACT: This paper presents Chierchia (2013)'s conjecture, according to which the distribution and interpretation of scalar items, free choice, polarity item and implicatures are conditioned by the logical context in which they occur. In downward entailment contexts, the exaustification of the alternatives does not generate a grammatical contradiction, whereas in upwards contexts, exaustifying the alternatives leads to a grammatical contradiction. We show that the conjecture rightly predicts intuitive judgments of those items in Brazilian Portuguese and explains the experimental results found by Pires (2018) on the behavior of modals in Brazilian Portuguese.

KEYWORDS: Alternative semantics. Chierchia's conjecture. Indefinites. Modals. Logic.

\section{INTRODUÇÃO}

O objetivo deste artigo é apresentar a conjectura de Chierchia (2013) em Logic in Grammar, seus desdobramentos mais recentes (CHIERCHIA, 2019 entre outros) para a nossa compreensão sobre as línguas naturais, e verificar ainda que informalmente se a hipótese explica os dados do Português Brasileiro (PB). O projeto de Chierchia é entender o que um falante sabe quando sabe usar itens como any em inglês ou qualsiqui em italiano. Esse é um conhecimento trivial, já que qualquer falante, incluindo crianças bem jovens, sabem usar signiticativamente esses itens. A primeira seção ilustra a complexidade desse conhecimento que todos nós temos, que faz parte do nosso dia a dia, discutindo o problema da projeção das pressuposições que, segundo algumas pesquisas atuais, pode também ser explicado pela conjectura ${ }^{1}$.

Na segunda seção, apresentamos a conjectura de Chierchia (2013) que pretende explicar vários fenômenos de significado - os itens de polaridade (any), as implicaturas escalares (some), os itens escalares (even), as pressuposições de factividade, os minimizadores (at all em inglês) -, através das línguas. A análise empírica desses fenômenos leva o autor a propor a hipótese de que os falantes são sensíveis a propriedades lógicas, computam alternativas e escolhem aquela que é mais informativa, sem, obviamente, ter consciência de que sua mente está operando dessa maneira. A seção termina apresentando resultados experimentais para sentenças encaixadas no inglês, que suportam a conjectura e, se corretas, mostram que essa computação não ocorre apenas após o processamento do significado da sentença (como é na visão griceana clássica), mas em certas posições sintáticas, no CP de sentenças encaixadas.

A terceira seção apresenta os resultados do experimento piloto de Pires (2018) para o par pode e deve no Português Brasileiro, que indicam que os falantes se comportam como o esperado pela conjectura. Discute ainda alguns exemplos de indefinidos no Português Brasileiro cuja distribuição e interpretação também confirmam a conjectura. O objetivo da seção é exemplificar intuições que devem ser exploradas empiricamente, tanto via análise de corpora, quanto via experimentos. Se a projeção de pressuposições nos factivos se explicar por mecanismos similares, então não só o rol de fenômenos explicado é impressionante, mas eles ocorrem através das línguas, indicando que estamos lidando com propriedades universais. Finalmente, se crianças com menos de 3 anos sabem usar seus anys ${ }^{2}$, então estamos diante de mais um argumento para a pobreza de estímulos.

\section{O CONHECIMENTO SEMÂNTICO}

Manuais contemporâneos (CHIERCHIA, 2003) introduzem a semântica como o estudo da capacidade que qualquer falante de uma língua natural tem de compreender qualquer sentença de sua língua. Essa capacidade matura muito cedo nas crianças e há evidências

\footnotetext{
${ }^{1}$ Romoli (2012) e D’ Avila (2017) para os factivos no Português Brasileiro.

${ }^{2}$ Não sei de trabalhos sobre a aquisição desses indefinidos no PB. Sem dúvida alguma essa é uma lacuna a ser preenchida.
} 
de lesões e deficiências que afetam o seu funcionamento. ${ }^{3} \mathrm{Um}$ falante sabe interpretar sentenças da sua língua, atribuir condições de verdade, calcular com expectativas sobre o ouvinte, sobre como ele irá interpretar, sobre o contexto em que o proferimento ocorre e sobre o que está sendo dito (GRICE, 1975). Sabe compor e decompor as unidades de significado. Essa é uma capacidade complexa. Nesta seção, discutimos o problema da projeção das pressuposições. ${ }^{4}$

Qualquer falante do português, mesmo que nunca tenha ouvido a sentença em (1), entende o que ela significa, sabe em que contexto ela ocorre com felicidade e sabe decompô-la em unidades:

O João lamenta que Maria morreu.

Sem entrar em detalhes, podemos imaginar que as unidades são João, lamenta e Maria morreu. João é o nome do indivíduo João. Maria morreu denota um fato no mundo e o verbo conjugado lamenta é de atitude proposicional porque indica a posição do sujeito em relação ao fato denotado pela sentença encaixada. Assim podemos descrever a sentença em (1) como em (1'): Lamenta j, $\mathrm{p}_{1}$

Em que $p_{1}$ é a proposição expressa por Maria morreu e jé o indivíduo de nome João. Se negarmos a sentença em (1), como em (2a), mantemos que a Maria morreu e alteramos a relação que o João entretém com esse fato. Em (2a), o João não lamenta a morte dela. A negação atua sobre o lamento e não nega o fato de que a Maria morreu, conforme representação em (2b):
a. O João não lamenta que a Maria morreu.
b. $\quad$ Não (Lamenta $\left.j, p_{1}\right)$

Assim, tanto (1) quanto (2) pressupõe que (3) é verdadeira:

$$
\text { Maria morreu. }\left(=\mathrm{p}_{1}\right)
$$

(3) é uma pressuposição de (1) e de (2) porque para que essas sentenças tenham valor de verdade é preciso que ela seja verdadeira. Verbos como lamentar são chamados de factivos pois pressupõem um fato. Em outros termos, alguém só profere (1) ou (2) com felicidade em contextos em que é verdade que Maria morreu ${ }^{5}$. Assumimos implicitamente que a pressuposição é verdadeira, que ela é satisfeita no contexto de fala e atualizamos o contexto com a informação sobre o estado de espírito do João (em (1), ele lamenta, em (2), não lamenta).

O problema da projeção das pressuposições é explicar porque em alguns contextos essa inferência é suspensa. Considere a sentença em (4):

$$
\text { Se a Maria morreu, então o João lamenta que a Maria morreu. }
$$

Em (4), (3) foi filtrada: (3) não faz parte do fundo conversacional compartilhado. O falante não se compromete com a morte de Maria. Se a pressuposição está codificada no item lexical lamentar, então somos obrigados a concluir que (4) acarreta que a Maria morreu, mas essa é uma conclusão indesejável porque não é essa a nossa intuição. Como explicar que em alguns casos projetamos a pressuposição e em outros não? Esse é um conhecimento sofisticado.

Note o paralelismo com os verbos chamados aspectualizadores como parar de:

\footnotetext{
${ }^{3}$ Crain e Thornton (2013) para pesquisas com crianças.

${ }^{4} \mathrm{O}$ leitor interessado na formalização dentro do quadro da semântica dinâmica ver capítulo 10 de Chierchia (2003) para uma boa introdução.

${ }^{5}$ Há a negação metalinguística, não lamenta porque a Maria não morreu. Não iremos nos deter nessa questão.
} 

a. João parou de fumar.
b. João não parou de fumar.
c. João fumava
d. Se João fumava, então ele parou de fumar.

(5a) e (5b) pressupõem que (5c) é verdadeira. Mas (5d) não. Assim, a pressuposição que parece estar associada ao aspectualizador parar de não se projeta.

Se a conjectura de Chierchia está certa, o que explica quando bloqueamos as pressuposições é um raciocínio inferencial sensível ao contexto e guiado por uma máxima que procura sempre por mais informação ao exaurir alternativas. Fazemos isso sem pensar, naturalmente. Mais fantástico ainda, parece que as crianças computam esses raciocínios ainda muito jovens. A próxima seção apresenta a conjectura.

\section{A CONJECTURA DE CHIERCHIA}

A conjectura de Chierchia (2013) procura dar uma explicação única para fenômenos considerados díspares, tendo como pano de fundo a variação entre as línguas e a aquisição da linguagem. Entre os fenômenos estão: as implicaturas escalares presentes em itens como some, e or; os indefinidos de polaridade e de livre escolha, como o any em inglês; as pressuposições e as expressões minimizadoras como give a damn. Para entender a conjectura, considere o padrão distribucional de any no inglês:
a. $\quad{ }^{*}$ There is any cookie left.
b. There isn't any cookie left.
c. If there is any cookie left, we are lucky.
d. $\quad{ }^{\star}$ If we are lucky, there is any cookie left.

Em (6) temos dois pares mínimos: (6b) nega (6a) e a única diferença entre (6c) e (6d) é onde aparece o item de polaridade any, no antecedente ou no consequente do condicional. Se a conjectura de Chierchia está correta, então a restrição na distribuição do any é semântica e se explica porque o sistema, ao processar uma operação de exaustão, disparada pela presença de alternativas, em contextos com propriedades lógicas distintas, leva a resultados diferentes.

A conjectura é que as expressões são sensíveis a uma propriedade de conjuntos, que, combinada a uma operação de exaustificação das alternativas e um princípio de maximizar a informação, gera uma contradição quando processa (6a) ou (6d). Assim, o que bloqueia essas sentenças não é a sintaxe, mas o fato de que any ocorre em contexto de acarretamento para cima; essa computação leva ao que Chierchia chama de Trivialmente-Gramatical, uma contradição linguística. Chierchia distingue a contradição gramatical das contradições lógicas que ocorrem em exemplos como Maria é e não é legal. Na contradição lógica é sempre possível re-interpretar de forma a torná-la não contraditória e passível de ser verdadeira: por exemplo, a Maria é legal em alguns aspectos e não é legal em outros. A trivialidade gramatical não é cancelável, porque não depende do que os predicados significam, mas apenas das operações. Na contradição lógica precisamos ter o mesmo predicado afirmado e negado (ser legal e não ser legal, no exemplo); na contradição gramatical esse não é o caso porque ela é cega para o predicado, enxergando apenas as deduções. Ela é efetivamente semântica.

Afirmativas e consequentes de condicional são contextos de raciocínio do conjunto para o superconjunto, chamado de acarretamento para cima, enquanto que a negação e o antecedente do condicional, (6b) e (6c), são contextos de acarretamento para baixo, isto é a relação de acarretamento se dá do conjunto para o subconjunto. Quando exaurimos as alternativas nesses contextos produzimos resultados distintos por causa das relações lógicas. Em contextos para cima, vamos gerar uma contradição; em contextos para baixo, o proferimento dá o máximo de informação, assim exaurir as alternativas é trivial. 
O quantificador every no inglês e também o todo no português são contextos de acarretamento para baixo no sintagma nominal e de acarretamento para cima no sintagma verbal. Se (7a) é verdadeira, (7b) também é, mas (7c) não se segue de (7a). Assim, a primeira parte de um quantificador universal como every, que corresponde ao Sintagma Nominal, SN, é um contexto de acarretamento para baixo, inferimos do conjunto para o subconjunto. Mas a segunda parte do quantificador universal, o Sintagma Verbal, SV, é um contexto de acarretamento para cima. Assim, (7a) acarreta (7d) e não acarreta (7e). Em contexto de acarretamento para cima, inferimos do conjunto para o super-conjunto:
a. Every student smokes.
b. Every student who is blonde smokes.
c. Everyone smokes.
d. Every student does something.
e. $\quad$ Every student smokes a pipe.

(7a) acarreta apenas (7b) e (7d). Em (7b) a relativa determina um subconjunto de alunos; o contexto é de acarretamento para baixo, do conjunto para o subconjunto. Em (7d), vamos do conjunto dos fumantes para o super conjunto daqueles que fazem algo. Esse é um contexto de acarretamento para cima. Temos então:

$\begin{array}{ccc}\text { Every } & \downarrow & \uparrow \\ & \text { SN } & \text { SV }\end{array}$

A predição é que any (e outras expressões) é licenciado apenas em contextos de acarretamento para baixo; no caso de se combinar com every, apenas quando any aparece no SN, a sentença é gramatical. Se any ocorre no SV, a sentença é agramatical. Isso ocorre, como veremos, porque em contextos de acarretamento para cima, exaurir as alternativas leva a uma contradição. Apenas em contexto de acarretamento para baixo a interpretação com as alternativas exauridas é mais informativa. A predição quanto ao contraste de gramaticalidade de any com o quantificador universal every encontra respaldo empírico e experimental (Panizza et al., 2009, entre outros):

(8) avery student who read any paper by Chierchia knows that he is a semanticist.

b. $\quad *$ Every student who knows that Chierchia is a semanticist, read any paper by him.

A hipótese prediz que o any vai ser aceito na primeira parte de every e rejeitado na segunda parte de every, no sintagma verbal. Se essa hipótese está correta, então o nosso sistema de interpretação presta atenção não apenas em propriedades de conjunto, mas faz isso porque ao exaurir as alternativas compara se o resultado é forte informacionalmente ou se gera contradição. Vamos então retomar (6a) e (6b). A negação, exemplificada em (6b), repetida em (9a) por conveniência, é um contexto de acarretamento para baixo, em que vamos do conjunto para o subconjunto. O any $N$ é um sintagma indefinido que tem um domínio mais amplo do que o indefinido $a \mathrm{~N}$, que é a sua alternativa. ${ }^{6} \mathrm{O}$ significado de (6b) está em (9b). O conjunto das alternativas representadas pelo indefinido está em $(9 \mathrm{c})$ :
a. There isn't any cookie left.
b. $\quad \neg \exists \mathrm{x} \in \mathrm{D}$ [bolacha $(\mathrm{x}) \wedge \operatorname{sobrou}(\mathrm{x})]$
c. $\quad\left\{\neg \exists \mathrm{x} \in \mathrm{D}^{\prime}[\right.$ bolacha $\left.\quad(\mathrm{x}) \wedge \operatorname{sobrou}(\mathrm{x})]: \mathrm{D}^{\prime} \subseteq \mathrm{D}\right\}$

(9a) diz que não existe algo que esteja no domínio mais amplo D tal que esse algo é bolacha e sobrou, isto é o que aparece em (9b). Imagine que o domínio D é a cozinha. Assim, temos que não há bolachas em nenhum lugar da cozinha. O conjunto de alternativas em (9c) tem um domínio mais restrito, por exemplo, o armário de mantimentos, a geladeira, o fogão. (9b) acarreta as alternativas em (9c): se D é mais amplo que D’, se não há bolacha na cozinha em lugar algum, tem que ser o caso que não há bolacha no armário de mantimentos, não há na geladeira e assim por diante. $\mathrm{O}$ operador de exaustificação nega todas as alternativas que não são

${ }^{6}$ Veja Kadmon \& Landman (1993) sobre a semântica de any. 
acarretadas pela sentença proferida, já que os acarretamentos são parte da proposição expressa e não podem portanto ser retirados ("the entailments of a proposition are part of its truth conditional content: they cannot be severed from it" (CHIERCHIA 2013, p. 38)). Todas as alternativas em (9c) são acarretadas por (9b) que é mais forte. Logo, exaurir as alternativas vai ser vácuo, porque o falante já disse algo mais forte informacionalmente. Usar o any nesse contexto é altamente informativo.

Compare com o que ocorre com (6a), repetida em (10a). O significado da sentença está em (10b). A alternativa é o conjunto de proposições veiculado pelo indefinido a $N$, em (10c). Suponha mais uma vez que D seja o conjunto de lugares na cozinha, como exemplificado em (10d). Nenhuma das sentenças em (10d) é acarretada por (10b), que afirma que há bolacha no domínio mais amplo. Daí não podemos concluir que elas estão na geladeira ou no armário... Logo, todas as alternativas serão exauridas pelo operador e o resultado será não sobrou bolacha na geladeira, não sobrou bolacha na mesa da cozinha e assim por diante:

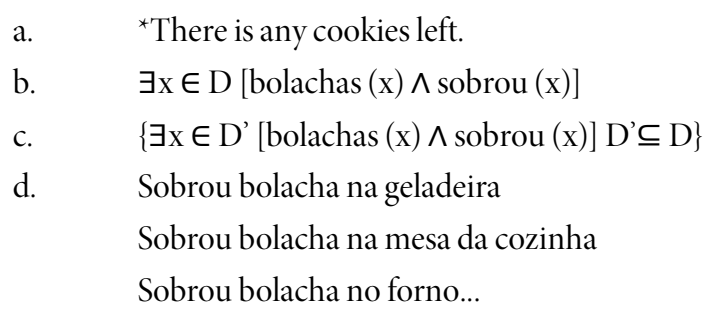

Ao exaurir as alternativas que não são acarretadas por (10a), todas as que estão em (10d), o resultado é que elas são automaticamente negadas: não sobrou bolacha na geladeira, não sobrou bolacha no forno... Mas daí chegamos numa contradição porque é verdade que sobrou bolachas, (10a) é verdadeira, mas não sobrou bolacha em lugar algum da cozinha... A sentença gera uma contradição semântica, mesmo que não tenhamos qualquer consciência do que está acontecendo.

Resumindo: any $N$ indica que o ouvinte deve considerar o domínio mais amplo em relação ao conjunto de alternativas denotado pelo sintagma a $\mathrm{N}$; de tal forma que o domínio de anyé mais amplo do que o domínio do indefinido (D contém D’). Num contexto de acarretamento para cima, chegamos a uma contradição. Assim, a sentença em (6a) está excluída pelo componente semântico porque gera uma contradição. Isso não ocorre em (6b) porque a negação é um contexto de acarretamento para baixo que inverte a escala de alternativas. Se não há uma bolacha no domínio maior, então também não há no domínio menor. Exaurir as alternativas não leva a nada porque ampliar o domínio na negação é mais informativo.

\subsection{RESULTADOS EXPERIMENTAIS}

A literatura sobre os itens escalares e implicaturas em inglês já dispõe de uma boa quantidade de pesquisas experimentais, incluindo rastreamento ocular e EEGs (eletroencefalogramas), assim como comparação entre crianças e adultos. Há trabalhos experimentais sobre o inglês e o italiano, em sua maior parte, que buscaram testar se efetivamente os falantes se comportam diferentemente com relação aos contextos de acarretamento para baixo e para cima. Os resultados têm apontado para uma resposta positiva: os falantes se comportam diferentemente quando estão em contexto de acarretamento para baixo ou para cima (PANIZZA et al., 2009, por exemplo). ${ }^{7}$

Uma consequência da proposta teórica de Chierchia e que está sendo testada experimentalmente para o inglês diz respeito ao encaixamento. Se há um exaustor e esse operador tem escopo amplo sobre a proposição, então se espera que ele ocorra em posições sintáticas que correspondem ao CP, isto é, a implicatura pode ser computada na sentença encaixada. A versão griceana clássica sobre as implicaturas entende que elas são computadas globalmente, apenas após o processamento da sentença como um todo. Assim há previsões diferentes para (11). Na teoria gramatical das implicaturas, proposta por Chierchia e outros (CHIERCHIA et al, 2012), há duas posições que o operador de exaustão, representado por $\mathrm{O}$, já que se comporta como um only silencioso, pode ocupar, como representado abaixo em (11a):

${ }^{7}$ Os trabalhos experimentais sobre esse fenômeno são poucos e a maioria sobre o inglês e o italiano. Não há dúvidas de que mais pesquisas são necessárias. 
João acredita que algum aluno fuma.
a. $\quad \mathrm{O}[$ João acredita $\mathrm{O}$ [algum aluno fuma] $]$
b. $\quad \mathrm{O}[$ João acredita algum aluno fuma]

Se a proposta de Chierchia está correta, então, há dois lugares para que a operação de exaustão das alternativas seja computada: no CP externo e no CP interno, como mostra (11a). Na proposta griceana clássica, a implicatura em (11) ocorre somente após o processamento da sentença como um todo, (11b).

Chemla e Spector (2011) propõem um experimento para testar qual das teorias melhor prediz o comportamento interpretativo dos falantes de inglês. (12) é um exemplo do experimento realizado por esses autores:

Every letter is connected with some of its circle.

Cada letra está conectada com algum dos círculos.

Leia essa sentença e avalie a sua intuição nos seguintes cenários:

Experimental embedded scalar implicatures E. Chemla \& B. Spector

Figure 4: Illustrative examples of the images used to illustrate the different conditions
FaLsE, LITERAL, WEAK and strong for the test sentence (8): 'Every letter is connected
with some of its circles'. We also reported below each image whether the literal (Lit),
global (Glob) and local (Loc) readings are true (T) or false (F).

Figura 1: Exemplos e cenários

Fonte: Chemla EeSpector (2011)

Os cenários são:

(i) o cenário em que a sentença é falsa porque há letras que não estão conectadas a nenhum círculo (false);

(ii) o cenário literal, em que todas as letras estão conectadas com todos os círculos. A previsão de ambas as teorias é que os falantes avaliem que a sentença (12) é falsa nessa situação porque a interpretação é enriquecida com a implicatura, algum mas não todos. Atribuir verdadeiro nesse cenário é interpretar literalmente, i.e. o sentido fraco e portanto semântico (alguns e talvez todos). Semanticamente, a sentença expressa que cada letra está conectada com pelo menos um dos círculos.

(iii) no cenário representado à direita embaixo, está a interpretação forte, em que todas as letras estão conectadas a algum círculo, mas não a todos. A predição para ambas as teorias é que os falantes consideram que (12) é verdadeira nessa situação.

(iv) no cenário fraco, à esquerda embaixo, algumas letras estão conectadas a todos os círculos e outras conectadas a alguns. É somente nesse caso que as teorias fazem predições distintas. A previsão para a teoria gramatical é que a sentença seja considerada 
falsa nesse contexto; ao passo que a teoria globalista considera que ela é verdadeira nesse cenário. Para interpretar a sentença como falsa, o falante deve estar computando a implicatura dentro da sentença (alguns mas não todos).

Chemla e Spector concluem que falantes de inglês se comportam como esperado pela teoria gramatical. Sem dúvida alguma é preciso replicar esse experimentos e propor novos.

\section{O DADOS NO PORTUGUÊS BRASILEIRO}

O objetivo dessa seção é investigar se a conjectura se mantém para alguns dos itens no PB. A investigação é exploratória e precisa ser sistematizada. A literatura sobre as implicaturas escalares é extensa e não vamos revisá-la. O exemplo clássico no PB mostra que a interpretação de algum segue o padrão previsto pela conjuntura. A sentença em (13a) é comumente interpretada como (13b):

(13) al Algum aluno tirou 10 na prova.

b. Nem todos os alunos tiraram 10 na prova.

Como sabemos, (13b) é uma implicatura e não um acarretamento de (13a), afinal é possível cancelar a interpretação em (13b). Um contexto em que (13a) é verdadeira e (13b) é falsa é uma situação de conhecimento parcial. O falante teve evidência factual de que alguns dos alunos tiraram 10 na prova, mas não viu todas as notas; as que ele viu eram 10, logo, ele proferiu (13a) com segurança. No entanto, de fato todos os alunos tiraram 10 na prova. Essa é uma situação em que (13a) é verdadeira, (13b) é falsa. Logo não há acarretamento entre elas, mas implicatura. A derivação da implicatura em (13) foi motivo de muitos estudos e sabemos hoje em dia um passo a passo que leva do significado da sentença em (13a), em que se afirma a existência de pelo menos um aluno que tirou 10 na prova, até a conclusão em (13b) de que esse não foi o caso para todos os alunos. ${ }^{8}$ Nesse raciocínio, o intérprete assume que o falante está sendo maximamente informativo e tem uma opinião. Se ele usou um item mais fraco, algum, é porque ele não tem evidências para usar a alternativa mais forte, todo. As alternativas formam as famosas escalas de Horn (1972), , na qual os itens estão ordenadas assimetricamente, <algum, todo >: o operador de exaustão exaure as alternativas que não foram ditas (ou acarretadas pelo que foi dito), e, juntamente com a crença de que o falante tem uma opinião, geramos a interpretação enriquecida de "algum aluno e não todos".

O ponto para entender o argumento de Chierchia é que há contextos em que não é natural fazermos a inferência em (13b), ou seja, há contextos que não favorecem a interpretação enriquecida em (13b) em que algum é interpretado de modo forte como "algum e não todos". Por exemplo, a sentença em (14a) não é naturalmente interpretada como (14b); a leitura preferencial é, na minha intuição, (14c):

(14) a. Todo aluno que leu algum dos livros da bibliografia foi bem na prova.

b. $\quad$ \# Todo aluno que leu algum e não todos os livros da bibliografia foi bem na prova.

c. Todo aluno que leu algum e talvez todos os livros da bibliografia foi bem na prova.

Não inferimos de (14a) que foi bem na prova quem leu só algum mas não todos os livros. Ao contrário, nossa tendência é achar que quem leu todos os livros da bibliografia foi muito melhor na prova. Nesse contexto, primeira parte de todo, algum tem leitura fraca, sem enriquecimento pragmático: "algum e talvez todos". Como vimos, a posição do SN em combinação com todo é um contexto de acarretamento para baixo. A conjectura de Chierchia é de que a oscilação da interpretação de itens escalares como algum ou ou se explica pelo tipo de propriedade lógica do contexto.

A predição é que a sentença em (15a) seja interpretada como em (15c), em que não há computação da inferência em (15b):

$$
\text { a. Se algum político vota a favor da portaria, o governo libera a verba. }
$$

${ }^{8}$ Veja Pires de Oliveira e Basso (2014). 
b. \# Se algum político e não todos vota a favor da portaria, o governo libera a verba.

c. Se algum político e talvez todos vota a favor da portaria, o governo libera a verba.

Enquanto que (16a) aciona o raciocínio em (16b), fortalecendo o que está sendo dito:

(16) a. Se o governo libera a verba, algum político vota na portaria.

b. Se o governo libera a verba, algum político e não todos vota na portaria.

c. \# Se o governo libera a verba, algum político e talvez todos aprova a verba.

A minha intuição se conforma com a expectativa. A melhor interpretação para (15a) é a interpretação fraca de algum, i.e. algum e talvez todos, em (15c). Essa é a interpretação que é gerada sem que a inferência seja computada. Minha interpretação oscila para (16a), embora eu tenda a escolher (16b) como a melhor interpretação.

Pires (2018) testou o comportamento dos falantes para verificar a conjectura de Chierchia com um par de itens escalares que não foram muito estudados na literatura experimental sobre as implicaturas nem mesmo no inglês, embora eles apareçam na lista de itens escalares em Horn: os modais de possibilidade e de necessidade. Itens escalares estão em relação de acarretamento assimétrico: tem que acarreta pode mas pode não acarreta tem que, representado por <pode, tem que >. Se a teoria de Chierchia sobre a distribuição e interpretação de expressões escalares está correta, então deve haver uma variação na interpretação na interpretação de pode que não é aleatória. Por hipótese, pode é interpretado como "pode e não tem que" em contextos de acarretamento para cima, porque esse é o sentido enriquecido. Em contextos de acarretamento para baixo, a predição é que a implicatura não seja computada, em outros termos, a interpretação de pode é fraca "pode e talvez tenha que". Em seu trabalho de Iniciação Científica, Pires testou experimentalmente essa hipótese, replicando em parte o desenho experimental encontrado em Panizza et. al (2009) para a testagem de implicaturas escalares para os numerais.

O experimento compara os contextos de acarretamento para baixo e para cima nas duas posições dos itens todo e se. A hipótese é de que a interpretação irá oscilar segundo o padrão: interpretação enriquecida no contexto de acarretamento para cima para os dois itens e interpretação fraca no contexto de acarretamento para baixo também para os dois itens. No caso de todo, o sentido enriquecido ocorre no SV e o sentido fraco no SN. Para o se, o sentido fraco está no antecedente e o enriquecido no consequente. Considere os exemplos em (17), sentenças alvo desse piloto:

a. Se o João pode votar, ele vai sair cedo.

b. Se o João sair cedo, ele pode votar.

A hipótese é que (17a) vai ser interpretada fracamente (pode e talvez tenha que), enquanto em (17b) a interpretação é forte (pode e não tem que). Foram também analisados pares mínimos com todo, exemplificados abaixo:

a. Todo aluno que faltar na aula pode votar.

b. Todo aluno que pode votar vai faltar na aula.

(18b) deve ter a leitura fraca, sem a implicatura (pode e talvez tenha que); enquanto que (18a) a interpretação deve ser forte (pode e não tem que).

Cada sentença era seguida por duas opções de interpretação. Os participantes escolhiam apenas uma resposta: (1) pode e talvez tenha que; (2) pode e não tem que. ${ }^{9}$ Os testes foram disponibilizados na internet via Facebook. Havia sentenças controle e distratoras. Foram testadas 16 sentenças alvo. O teste foi respondido por 20 participantes, todos falantes nativos do português

\footnotetext{
${ }^{9} \mathrm{O}$ experimento pode ser acessado neste link:

https://docs.google.com/forms/d/1IcP5tjlkR-aQj_Vj0BWZCDFIcgfuCqgr097p_PW2YzM/edit?usp=sharing
} 
brasileiro. Os resultados desse experimento piloto indicam que a hipótese se sustenta: a interpretação oscila, e oscila conforme o esperado. Veja o gráfico abaixo, retirado de Pires (2018):

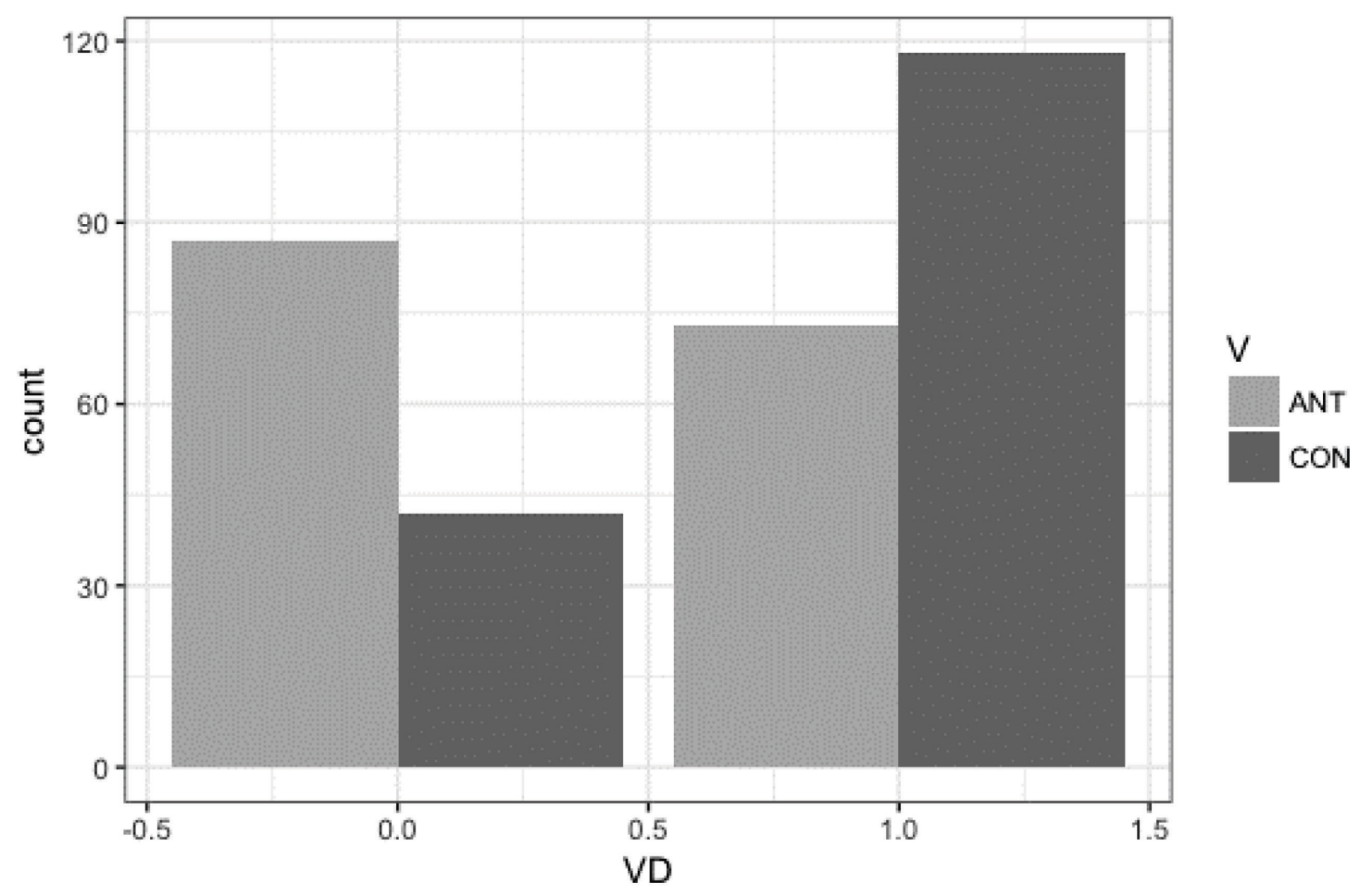

Gráfico 1: resultado de teste

Fonte: Pires (2018)

O gráfico reporta os resultados para todo e se agrupados, mas a análise isolada de cada item mostrou o mesmo padrão. Para compreender o gráfico é preciso entender que o bloco à esquerda com duas colunas representa os resultados de interpretação em contextos de acarretamento para baixo, isto é quando o item está no antecedente de se e no SN de todo. A coluna mais à esquerda, em avermelhada, indica a escolha da leitura fraca; na coluna à direita, em azulada, temos os participantes que atribuíram a leitura forte a sentenças com o pode no antecedente do condicional e na primeira parte do todo, (16a) e (17b), respectivamente. Há diferença estatisticamente significativa entre as respostas. Em outros termos, os falantes estão escolhendo a leitura fraca quando pode está no antecedente de se e no SN de todo.

No bloco à direita, temos os resultados para o consequente do condicional e a segunda posição, a posição do SV, para todo. Esses são contextos de acarretamento para cima. Note que houve uma inversão na tendência de interpretar. Agora os falantes preferem, significativamente, a leitura enriquecida, pode e não tem que.

Embora esse seja um experimento-piloto, ele indica que a interpretação do modal existencial no PB corrobora a hipótese de Chierchia (2013). Além disso esperamos que haja um contraste em itens de polaridade. A nossa intuição, que é a mesma de Ilari (1984), um precursor no estudos sobre os itens de polaridade no Português Brasileiro, indica uma diferença de aceitabilidade e de interpretação que corresponde ao contraste esperado:

(19) a. Ele não piscou o olho na aula hoje.

b. Ele piscou o olho na aula hoje.

c. Se o João piscou o olho na aula hoje, ele não entendeu a matéria.

d. Se o João não entendeu a matéria, ele piscou o olho na aula. 
A expectativa é que a leitura não composicional é acionada em (19a) e em (19c), enquanto que a leitura composicional ocorre em (19b) e (19d). O contraste deve aparecer também com outras expressões idiomáticas como (não) abriu a boca; (não) levantou um dedo pra ajudar. A conjectura deveria também explicar o comportamento e a distribuição de qualquer $N$ e também de um $N$ qualquer e sequer um N. Na minha intuição, há um contraste no diálogo abaixo - a resposta em (20c) à pergunta em (20a) é estranha; (20b) é natural:

(20) a. Você tem algum amigo?

b. $\quad$ Não tenho qualquer amigo. ${ }^{10}$

c. \# Tenho qualquer amigo.

Além disso, a predição é que qualqueré licenciado se aparecer na primeira posição de todo e não é tão aceitável se na segunda posição:

(21) a. Todo aluno que leu qualquer livro do Chierchia sabe que ele é semanticista.

b. $\quad$ \# Todo aluno que sabe que Chierchia é semanticista leu qualquer livro dele.

A minha intuição confere com o esperado: (21b) é marcada e (21a) é natural.

Finalmente, na minha intuição, há um contraste no exemplo em (22a) e (22b):

(22) a. Não vi aluno algum na palestra.

b. \#Vi aluno algum na palestra.

A primeira tarefa que precisamos realizar é um levantamento sistemático dos itens de polaridade no PB, Em seguida, é preciso verificar sua distribuição e interpretação, avaliar se os padrões se comportam segundo a conjectura de Chierchia e finalmente comparar com outras línguas.

\section{A LOGICIDADE DAS LÍNGUAS NATURAIS}

O objetivo deste artigo era explorar a conjectura de Chierchia (2013) para alguns dados do PB. Na primeira seção, exemplificamos como funciona o conhecimento semântico descrevendo brevemente o problema da projeção da pressuposição que talvez possa ser também explicado pela conjectura. A segunda seção apresentou a conjectura segundo a qual nosso sistema computa logicamente alternativas e avalia se exaurir as alternativas gera uma contradição/trivialidade gramatical. Analisamos a distribuição do any e apresentamos os resultados de um experimento sobre encaixamento que dá suporte à conjectura. A terceira seção, apresentou os julgamentos sobre dados do PB, assim como os resultados do experimento-piloto de Pires (2018) sobre a oscilação na interpretação de pode. Defendemos que essas são evidências que sugerem uma "máquina" que faz deduções lógicas. Mas esses são dados preliminares, precisamos de mais estudos.

Se a conjectura está no caminho correto, there is any cookies left é bloqueada porque gera uma contradição linguística, uma trivialidade-G(ramatical) e se as crianças já sabem usar itens de livre escolha como any com 3 anos (CRAIN; THORNTON, 1998), temos um argumento para a pobreza de estímulo. Essa rapidez para dominar regras complexas, que envolvem entender a diferença entre contexto de acarretamento para baixo e contexto de acarretamento para cima e computar alternativas e escolher a mais informativa sugere uma logicidade natural.

Inúmeras questões não são mais do que sugestões. Há necessidade de mais experimentos, com muitas línguas para podermos entender melhor as línguas e a mente humana.

${ }^{10}$ Há uma interpretação metalinguística que não estamos considerando. 


\section{REFERÊNCIAS}

CHEMLA, E.; SPECTOR, B. Experimental Evidence for Embedded Scalar Implicatures. Journal of Semantics, v. 28, p. 359-400, 2011.

CHIERCHIA, G. Semântica. Campinas: Editora da Unicamp, 2003.

CHIERCHIA, G. Logic in Grammar. Oxford: Oxford University Press, 2013.

CHIERCHIA, G. Factivity meets polarity: on two differences between Italian and English factives. In: ALTSHULER, D.; RETT, J. (org.) The Semantics of Plurals, Focus, Degrees, and Times. Springer, 2019. p. 111-134.

CHIERCHIA, G.; FOX, D.; SPECTOR, B. The grammatical view of scalar implicatures and the relationship between semantics and pragmatics. In: MAIENBORN, C.; VON HEUSINGER, K.; PORTNER, P. Semantics an International Handbook of Natural Language Meaning. v. III Berlin: Mouton de Gruyter, 2012.

CRAIN, S.; THORNTON, R. Acquisition of syntax and semantics In: TRAXLER, M.; GERNSBACHER, M. (ed.). Handbook of psycholinguistics. London: Elsevier, 1998, p. 1053-1110.

D’AVILA, A. Pressuposição e Implicaturas Griceanas: considerações sobre as inferências dos verbos factivos. Estudos Linguísticos e Literários, Salvador, $\quad$ n. $\quad 57, \quad$ p. 241-261, jul./dez.. $2017 . \quad$ Disponível em: https://portalseer.ufba.br/index.php/estudos/article/view/24712/15718. Acesso em: 20 abr. 2020.

GRICE, P. Logic and conversation. In: COLE, P.; MORGAN, J. (org.) Syntax and semantic 3: Speech Acts. New York: Elsevier Academic Press, 1975. p. 41-58.

HORN, L. R. On the semantic properties of logical operators in English. 1972. Dissertation (Doutorado em Linguística) - University of California, Los Angeles, 1972.

ILARI, R. Locuções Negativas Polares: Reflexões sobre um tema de todo mundo. In: Lingüística: questões e controvérsias. Série Estudos 10. Fac. Integrada de Uberaba, 1984. p. 83-97.

KADMON, N.; LANDMAN, F. A. Linguistics and philosophy, n. 15, p. 353-422, 1993.

NOVECK, I. A. When children are more logical than adults: experimental investigations of scalar implicatures. Cognition, n. 78, p. 165-188, 2001.

PANIZZA, D.; CHIERCHIA, G.; CLIFTON JR, C. On the role of entailment patterns and scalar implicatures in the processing of numerals. Journal of Memory and Language, n.61, p.503-518. 2009.

PIRES, B. Experimentos na Interface semântica-pragmática: os modais. Relatório de Iniciação Científica. UFSC. 2018.

PIRES DE OLIVEIRA, R.. BASSO, R. M. Arquitetura da conversação. São Paulo: Parábola Editorial, 2014. 
ROMOLI, J. Soft but strong. Neg-raising, soft triggers, and exhaustification. 2012. 282f. Tese (Doutorado em Filosofia) Departamento de Linguística, Universidade de Harvard, Cambridge, 2012. 